\title{
EXTRACTION AND ANALYSIS OF MAJOR AUTUMN CROPS IN JINGXIAN COUNTY BASED ON MULTI - TEMPORAL GF - 1 REMOTE SENSING IMAGE AND OBJECT- ORIENTED
}

\author{
Baiyang Ren ${ }^{1}$, Qiang Wen ${ }^{1, *}$, Huizhen Zhou ${ }^{2,1}$, Feng Guan ${ }^{1}$, Longlong $\mathrm{Li}^{1}$, Hong $\mathrm{Yu}^{1}$, Zhiyong Wang ${ }^{3}$
}

${ }^{1}$ Twenty-first Century Space Technology Applications Co., Ltd, Beijing 100096, China- (renby, zhouhz, wenqiang, guanfeng, lill, yuhong)@21at.com.cn

${ }^{2}$ State Key Laboratory of Earth Surface Processes and Resource Ecology, School of Natural Resources, Faculty of Geographical Science, Beijng Normal University, Beijing, China

${ }^{3}$ Beijing Engineering Research Center of Small Satellite Remote Sensing Information, Beijing, China - wangzy@21at.com.cn

KEY WORDS: Remote Sensing, Autumn Crops, Object-oriented, Information Extraction, Phenological Characteristics

\begin{abstract}
:
The purpose of this paper is to provide decision support for the adjustment and optimization of crop planting structure in Jingxian County. The object-oriented information extraction method is used to extract corn and cotton from Jingxian County of Hengshui City in Hebei Province, based on multi-period GF-1 16-meter images. The best time of data extraction was screened by analyzing the spectral characteristics of corn and cotton at different growth stages based on multi-period GF-116-meter images, phenological data, and field survey data. The results showed that the total classification accuracy of corn and cotton was up to $95.7 \%$, the producer accuracy was $96 \%$ and $94 \%$ respectively, and the user precision was $95.05 \%$ and $95.9 \%$ respectively, which satisfied the demand of crop monitoring application. Therefore, combined with multi-period high-resolution images and object-oriented classification can be a good extraction of large-scale distribution of crop information for crop monitoring to provide convenient and effective technical means.
\end{abstract}

\section{INSTRUCTION}

Remote sensing technology has been widely used in various fields of national economy and social development due to its macroscopic, comprehensive, dynamic and rapid characteristics. Among them, remote sensing technology for agriculture has developed rapidly, and it can timely and effective access to agricultural resources and agricultural production information, and also is the main technical method for the transition from traditional agriculture to information agriculture, overcoming the defects of manpower, material resources, financial resources and time lag in the traditional planting information statistics $(\mathrm{Li}$ et al., 2014).Provide effective help for a wide range of crop monitoring and provide an important basis for crop planting structure adjustment and optimization(Liu et al., 2014).

At present, many scholars have done a lot of research on crop information extraction based on multi-temporal remote sensing data (Ozdoganet al., 2010; Thenkabail et al., 2012; Vintrou et al., 2012).Verbeiren et al. extracted the spatial distribution information of Belgium's corn and wheat based on multitemporal SPOT images(Verbeirenet al., 2008).Zhang et al. used $\mathrm{TM} / \mathrm{ETM}+$ remote sensing image data of multi-temporal phases and 13 time-series MODIS EVI remote sensing image data to establish a decision tree identification model and extract main crops in Heilongjiang Province. (Zhang et al., 2012)Liu Kebao et al. utilized the multi-period RapidEye images to extract the spatial distribution of crop planting structure in Zhaodong City in 2011 based on the maximum likelihood supervised classification method(Liu et al., 2014).HaoWeiping et al. selected 14 MODIS NDVI images of major crops in 2007 in Northeast China and 2005 Landsat ETM $+30 \mathrm{~m}$ images and a large amount of ground survey data to extract the spatial information of the main crops based on unsupervised classification algorithm(Hao et al., 2011).However, most of the researches use the foreign remote sensing images to extract crops based on the pixel classification method and only use the spectral information of the images, making it difficult to distinguish between the categories of "same object different spectrums" and "same spectrum with different objects".

In this study, object-oriented information extraction method was used to extract corn and cotton, the main autumn crop in Jingxian County, Hengshui City, Hebei Province. Combining with the spectral characteristics, texture features, shape features, spatial relations and other eigenvalues of the object and the main crops phenology, based on domestic satellite image data multi-stage high score 16 meters image. As Jingxian County is located in the economically developed areas around Beijing and Tianjin, Bohai and Beijing-Tianjin, Shijiazhuang and Jinan Triangle economic centers, in recent years, Jingxian vigorously develops modern agriculture and strives to build a BeijingTianjin-Hebei high-quality crop base. Therefore, it is necessary to study Jingxiancounty crop planting structure and spatial distribution of information for Jingxian crop planting structure adjustment and optimization provide decision support. 


\section{STUDY AREA AND DATA}

\subsection{Study Area}

Jingxian County is located in the southeast of Hebei Province, the east of Hengshui City and the west bank of the Grand Canal, between $115^{\circ} 54^{\prime}-116^{\circ} 27^{\prime} \mathrm{E}$ and $37^{\circ} 28^{\prime}-37^{\circ} 51^{\prime} \mathrm{N}$. Horseshoe-shaped, part of the North China Plain, as shown in Figure 1, flat, the highest point of 25 meters above sea level, the

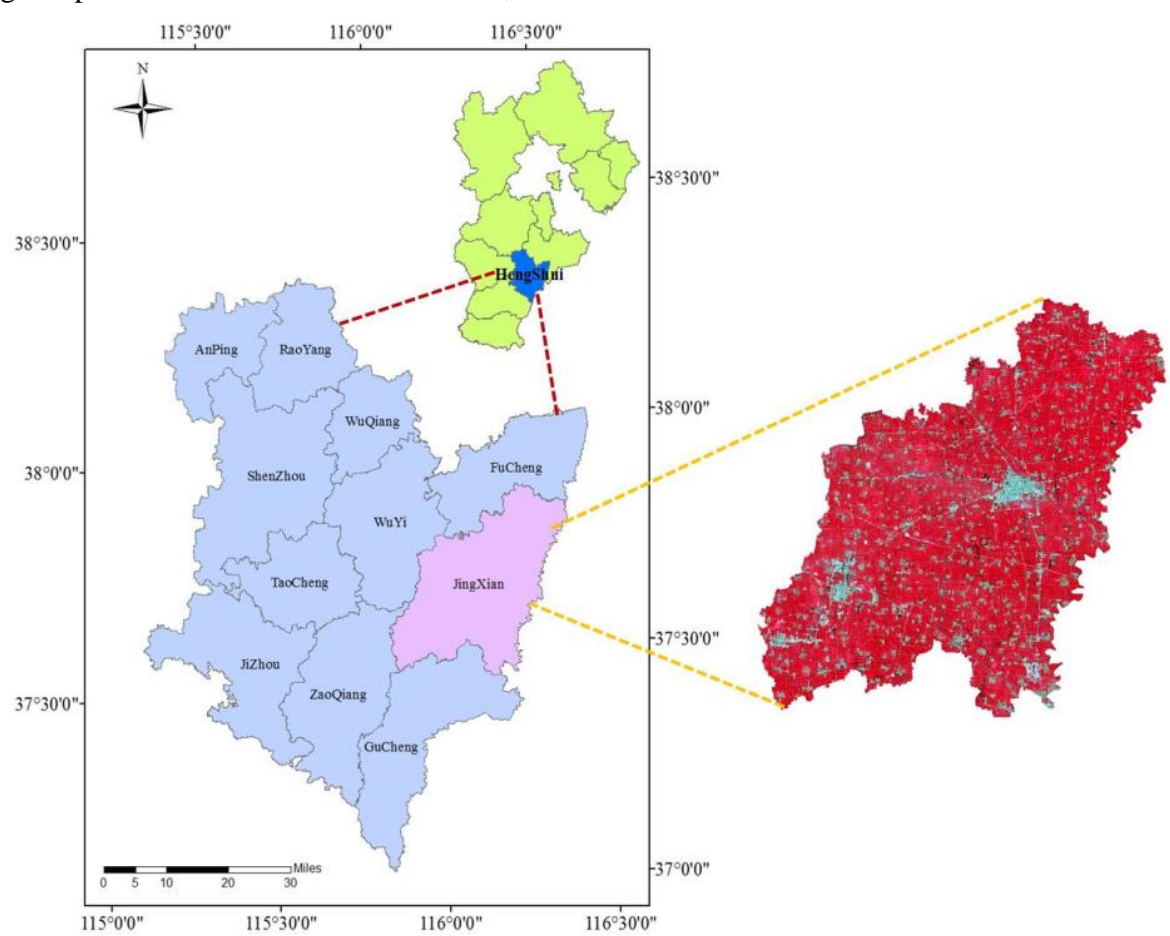

Figure 1. Location map for study area inHengshui City, Hebei Province, China

\subsection{Data}

The data used in this study mainly include remote sensing image data and other auxiliary data, as shown in Table 1 and Table 2 respectively.

\begin{tabular}{|c|c|}
\hline ImgaeAcquiringTime & Data Type \\
\hline $\begin{array}{c}\text { April } 25,2016 \\
\text { June } 22,2016 \\
\text { August } 27,2016 \\
\text { October } 14,2016\end{array}$ & $\begin{array}{l}\text { IF-1/WFV } \\
\text { (.img) }\end{array}$ \\
\hline \multicolumn{2}{|c|}{ Table 1.Remote sensing image data } \\
\hline Supplementary Data & Data Type \\
\hline $\begin{array}{c}\text { JingxianPhenology Information } \\
\text { JingxianAdministrative Border } \\
\text { Crop Statistics Data } \\
\text { JingxianAutumn CropQuadrat data }\end{array}$ & $\begin{array}{l}. \text { doc } \\
. \operatorname{shp} \\
. \text { doc } \\
. \text { shp }\end{array}$ \\
\hline
\end{tabular}

lowest point of 14.1 meters, the terrain slowly slopes from southwest to northeast, $45 \mathrm{~km}$ long from north to south, eastwest width of $27.5 \mathrm{~km}$. Jingxian is a warm temperate semihumid continental climate, the annual average temperature of $12.5{ }^{\circ} \mathrm{C}$, the average annual rainfall of $554 \mathrm{~mm}$, better agricultural base, crops mainly wheat, corn and cotton, is the national commodity grain production base counties.

\section{RESEARCH METHODS}

\subsection{Best Time Phase Data Selection}

The growth of crops follows a certain phenophase, and the spectral and texture characteristics of crops at different growth stages are different. Crop information extraction based on multitemporal remote sensing data, mainly based on different crop phenology differences, select the best time to distinguish crops. According to the phenological data of cotton, corn and interfering crops in Jingxian County, as shown in Table 3, the interpretation data of cotton, corn as shown in Table 4, the field survey data to determine the best image range for extracting cotton and corn, combined with the data quality analyzed to screen the key period images for cotton and corn extraction April 25, 2016, June 22, 2016, August 27, 2016, October 14, 2016, total 4 scenes GF-1images.

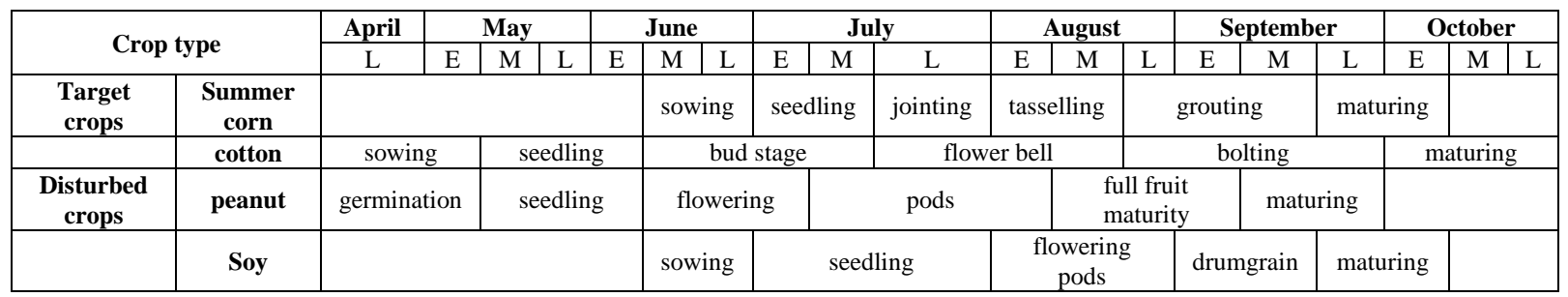

Table 3.The phenological table of autumn crops in Jingxian County 


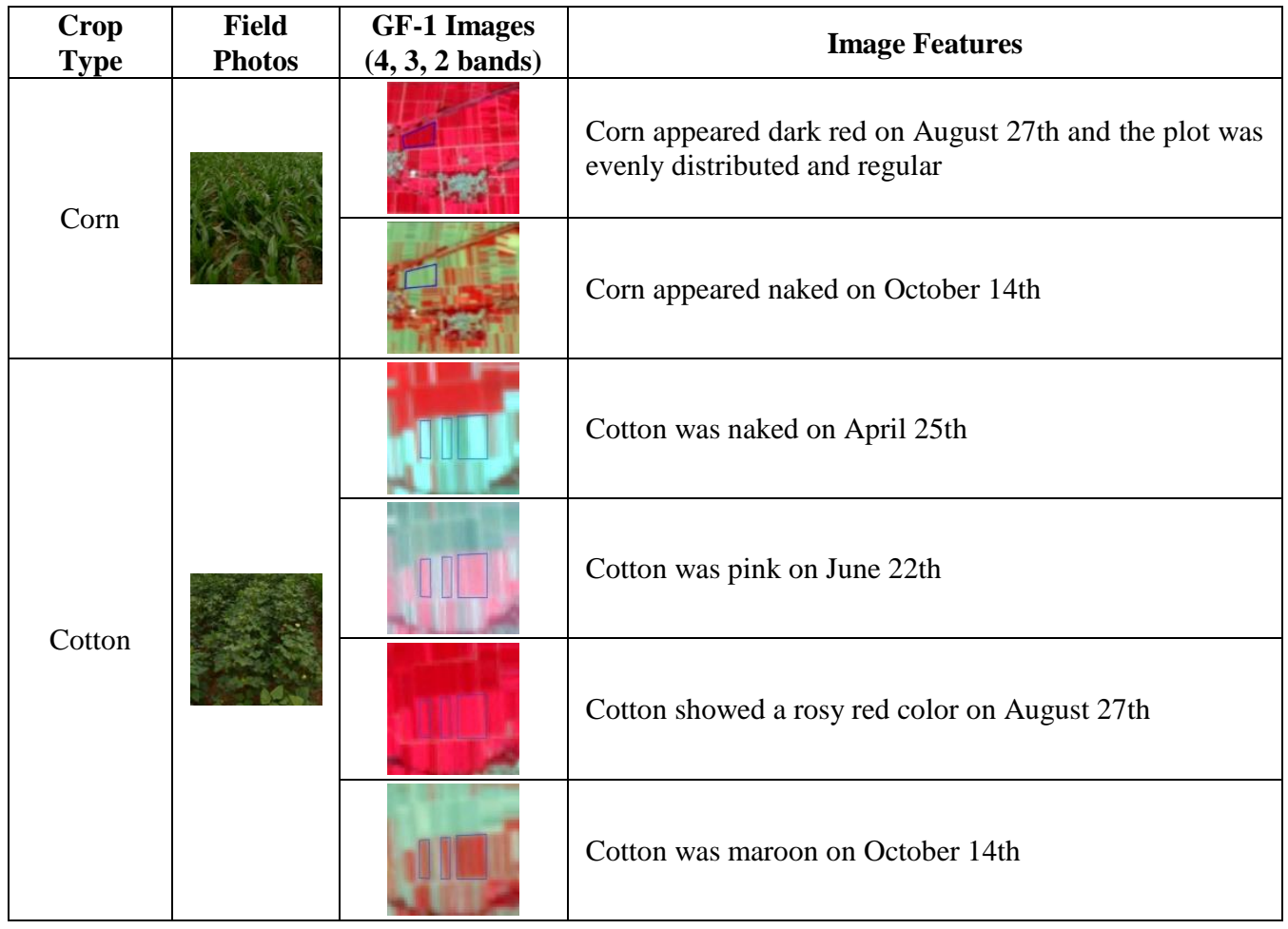

Table4.The characteristics of interpretation of main harvesting crops in Jinxian County

\subsection{Data Preprocessing}

Based on the phenological characteristics of corn and cotton, the major autumn crop in Jing County, four high quality GF-1/ WFV data were selected in this study. Due to the influence of the remote sensing system and the atmosphere, the acquired remote sensing images can not accurately record the information of complex underlying surfaces, which affects the

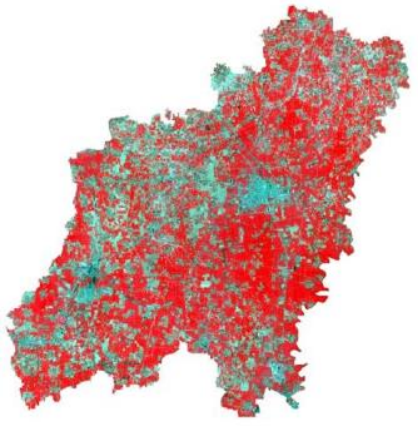

April 25, 2016

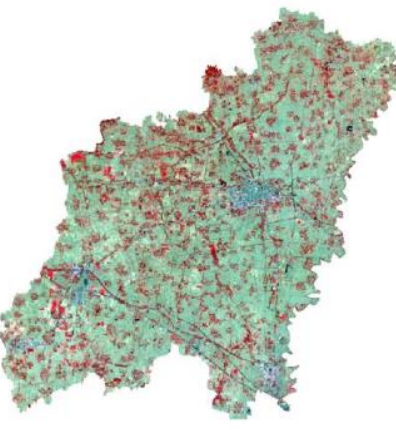

June 22,2016 accuracy of image analysis in remote sensing applications. Therefore, before the actual remote sensing image is used, the original image of the remote sensing needs to be pre-processed, including geometric correction and radiation correction to correct the distortion, blurring and noise generated in the process of remote sensing image acquisition. The preprocessed image is shown in Figure 2.
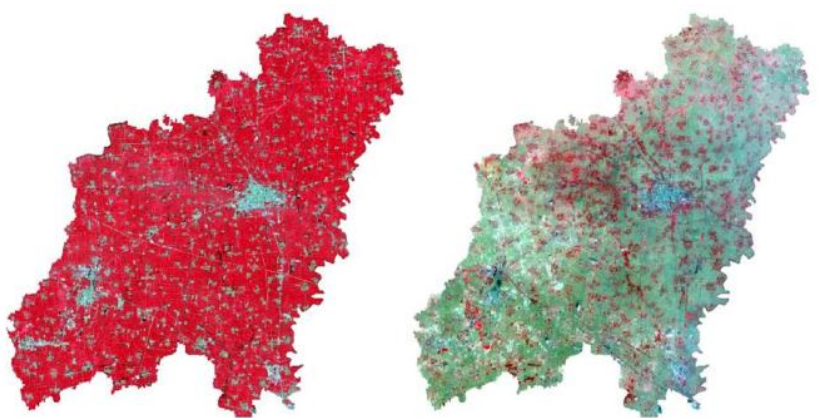

August 27, 2016

Figure 2. Preprocessing of remote sensing images

\subsection{Object-Oriented Information Extraction}

Based on the data of GF-1 / WFV (16 m) in the fourth stage, crop-based information extraction method based on object was used to extract the main autumn crop corn and cotton in Jingxian County, Hengshui City, Hebei Province.The objectoriented image analysis method combines the geometric features of spectral features, topological relations and shape factors of image to generate homogeneous image objects through image segmentation technology, which can reduce the pixels of wrong classification and overcome the problem of "synonyms spectrum" and "foreign body with the spectrum"phenomenon on the classification results, but also overcome the" salt and pepper "phenomenon in pixel-based information extraction ( $\mathrm{Li}$ et al., 2012; Ma et al., 2009), the main technical flow chart shown in Figure 3. 


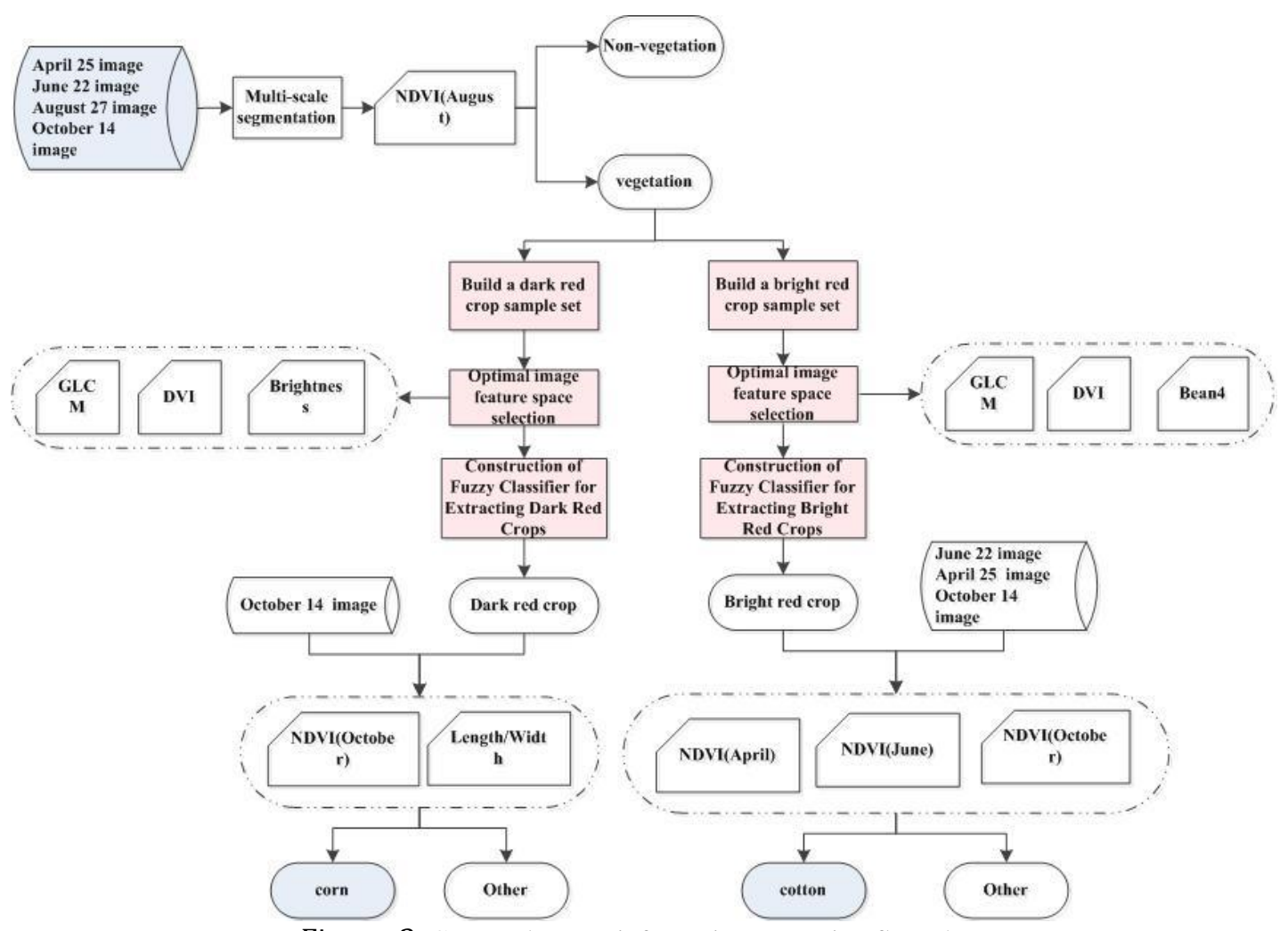

Figure 3. Corn and cotton information extraction flow chart

3.3.1 Image segmentation:Image segmentation is the core of object-oriented crop information extraction. The quality of the segmentation result will have an important influence on the feature parameters, which will affect the quality of classification results. The best segmentation result is that the segmentation object has good internal homogeneity, Neighboring objects have good heterogeneity. Based on the multi-scale segmentation algorithm in eCognition software, this study selects the optimal segmentation scale of crop information extraction by setting different band weights, spectral factors, shape factors and segmentation scales.Heterogeneity $f$ is calculated from the weighted sum of spectral and shape differences between two objects.

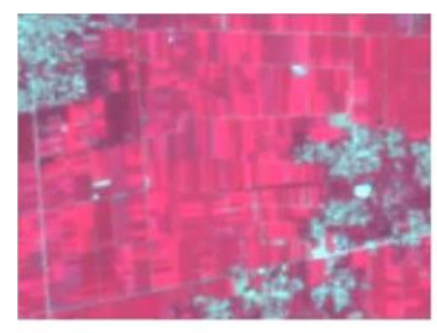

GF-1

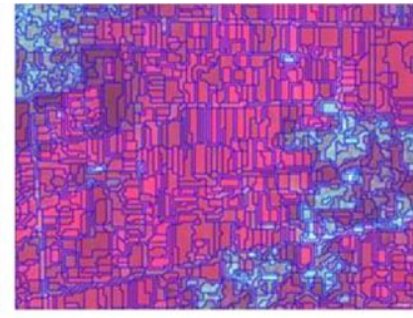

Scale 8

$$
f=w_{1} \mathrm{~g} h_{\text {color }}+\left(1-w_{1}\right) \mathrm{g} h_{\text {shape }}
$$

Where: $h_{\text {color }}$ is the spectral difference, $h_{\text {shape }}$ is the shape difference, $w_{1}$ is the spectral weight.

\begin{tabular}{ccc}
\hline $\begin{array}{c}\text { Segmentation } \\
\text { Scale }\end{array}$ & Smoothness & Tightness \\
\hline 8 & 0.8 & 0.2 \\
10 & 0.9 & 0.1 \\
15 & 0.9 & 0.1 \\
\hline
\end{tabular}

Table 5.Set split parameters

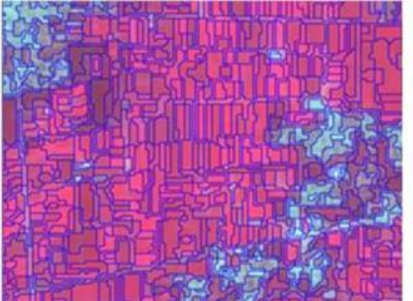

Scale 10

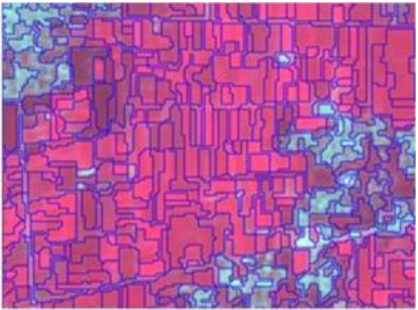

Scale 15

Figure 4 . Choose the best segmentation scale

3.3.2 Information Extraction: Based on the optimal segmentation object, a hierarchical classification method was adopted to construct the classifier layer by layer to extract the main crop corn and cotton in the study area.

\begin{tabular}{l|l|l|l} 
Layer & Category & Characteristic & Remarks \\
\hline
\end{tabular}

\begin{tabular}{|c|c|c|c|}
\hline & & parameters & \\
\hline \multirow[b]{2}{*}{ first layer } & vegetation & \multirow[b]{2}{*}{ NDVI } & \multirow{2}{*}{$\begin{array}{lr}\begin{array}{l}\text { Based on the } \\
\text { August } \\
\text { imagery }\end{array} \\
\end{array}$} \\
\hline & $\begin{array}{l}\text { Non- } \\
\text { vegetation }\end{array}$ & & \\
\hline \multirow[b]{2}{*}{$\begin{array}{l}\text { second } \\
\text { layer }\end{array}$} & $\begin{array}{ll}\text { Dark red } \\
\text { crop }\end{array}$ & $\begin{array}{l}\text { GLCM } \\
\text { Brightness }\end{array}$ & \multirow{2}{*}{$\begin{array}{l}\text { Based on the } \\
\text { vegetation in the } \\
\text { first layer and } \\
\text { the August } 27 \text { th } \\
\text { imagery }\end{array}$} \\
\hline & $\begin{array}{l}\text { Bright red } \\
\text { crop }\end{array}$ & $\begin{array}{l}\text { GLCM } \\
\text { DVI } \\
\text { Band4 }\end{array}$ & \\
\hline
\end{tabular}




\begin{tabular}{|c|c|c|c|}
\hline & corn & $\begin{array}{l}\text { NDVI } \\
\text { Length/Width }\end{array}$ & $\begin{array}{l}\text { Based on the } \\
\text { second layer of } \\
\text { dark red crops } \\
\text { and October } 14 \\
\text { images }\end{array}$ \\
\hline $\begin{array}{l}\text { third } \\
\text { layer }\end{array}$ & cotton & $\begin{array}{l}\text { NDVI(April) } \\
\text { NDVI(June) } \\
\text { NDVI(October) }\end{array}$ & $\begin{array}{l}\text { Based on the } \\
\text { second floor of } \\
\text { the bright red } \\
\text { crops and April } \\
25 \text { June } 22, \\
\text { October } \\
\text { images }\end{array}$ \\
\hline
\end{tabular}

Table 6.Build a classifier layer by layer

\subsection{Accuracy evaluation}

The error matrix was used to evaluate the information extraction results of autumn harvest corn and cotton in Jingxian County of Hebei Province. The flow chart of accuracy evaluation is shown in Figure 5.The first is the selection of checkpoints. When the checkpoints are selected, the checkpoints are classified according to the spatial distribution map of each crop, and then 100 checkpoints are drawn in layers.Second, combine the interpreting knowledge base and prior knowledge to carry out the calibration of the ground object types at random checkpoint, and use it as the reference data.Finally, the error matrix of the reference data and the classification results of each crop is calculated, and the accuracy evaluation results are obtained according to the overall accuracy, the producer precision and the user accuracy calculation formula.

\begin{tabular}{|c|c|c|c|c|c|}
\hline $\begin{array}{r}\text { Reference } \\
\text { data } \\
\text { Classified } \\
\text { data }\end{array}$ & Type 1 & Type 2 & $\cdots$ & Type n & Total \\
\hline Type1 & & & & & $\mathrm{x} 1+$ \\
\hline Type2 & & & & & $\mathrm{x} 2+$ \\
\hline$\ldots$ & & & & & $\ldots$ \\
\hline Typen & & & & & $\mathrm{xn}+$ \\
\hline Total & $\mathrm{x}+1$ & $\mathrm{x}+2$ & $\ldots$ & $\mathrm{x}+\mathrm{n}$ & \\
\hline & & & & & \\
\hline
\end{tabular}

Table 7.Error matrix

$$
\begin{gathered}
\text { Overall accuracy: } O A=\sum x_{i i} / N \\
\text { Producer accuracy: } P A=x_{i i} / x_{+j}
\end{gathered}
$$

$$
\text { User accuracy: } U A=x_{i i} / x_{i+}
$$

Where: $x_{i i}$ is the number of categorical data that is consistent with the reference data is on the diagonal; $N$ is the total number of check points; $x_{+j}$ is the total number of checkpoints in column $j ; x_{i+}$ is the total number of check points in row $i$.

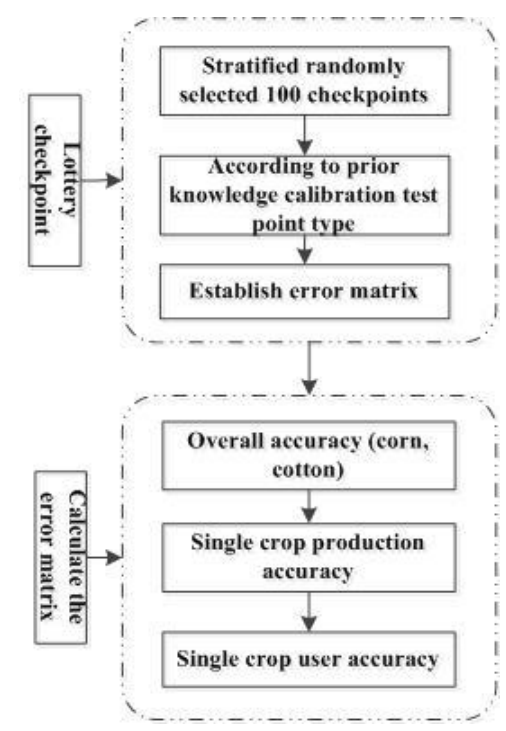

Figure 5. Precision evaluation flow chart

\section{RESULTS AND ANALYSIS}

\subsection{Precision evaluation results and analysis}

According to the accuracy evaluation method, we draw the distribution map of the crop yield of autumn harvest in 2016 in Jingxian County of Hebei Province, as shown in Figure 6, and the error matrix table, as shown in Table 8 , and according to the overall accuracy of corn and cotton producers' precision and User accuracy to evaluate the information extraction results, the overall accuracy of $95.7 \%$, indicating Jingxian County information extraction results are high, and for corn and cotton single class accuracy, respectively, by two types of crop producers and user accuracy to illustrate the accuracy of corn Producer accuracy is higher than the precision of cotton producers, indicating that cotton is more leakage than corn, but the user accuracy of corn is lower than the user accuracy of cotton, indicating that corn is more misclassified than cotton. 


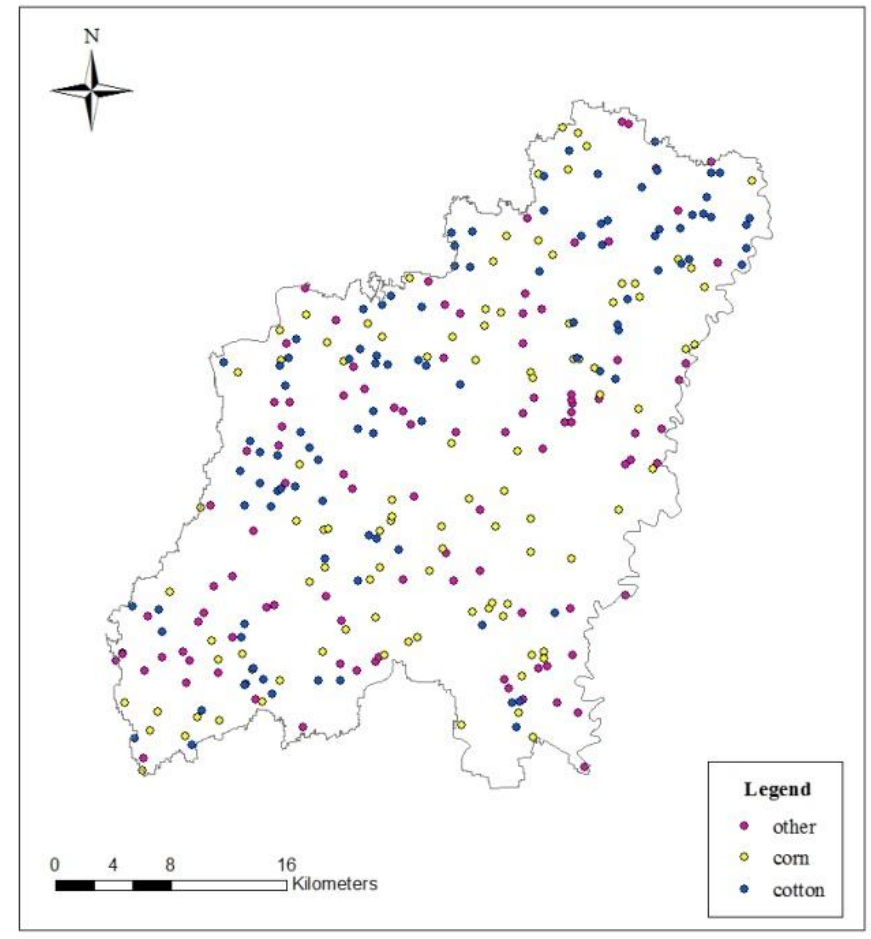

Figure 6.Autumn crop accuracy evaluation checkpoint distribution map in Jingxian County

\begin{tabular}{|l|l|l|l|l|}
\hline $\begin{array}{c}\text { Reference } \\
\text { data } \\
\text { Classiffed } \\
\text { data }\end{array}$ & corn & cotton & other & total \\
\hline corn & 96 & 3 & 2 & 101 \\
\hline cotton & 3 & 94 & 1 & 98 \\
\hline other & 1 & 3 & 97 & 101 \\
\hline total & 100 & 100 & 100 & 300 \\
\hline
\end{tabular}

Table 8.Error matrix

(1)Overall accuracy: $\mathrm{OA}=(287 / 300) * 100 \%=95.7 \%$

(2) single crop accuracy

1) corn

Producer accuracy: $\mathrm{PA}=(96 / 100) * 100 \%=96 \%$ (leakage error)

User accuracy: UA $=(96 / 101) * 100 \%=95.05 \%$ (misclassification error)

2) Cotton

Producer accuracy: PA $=(94 / 100) * 100 \%=94 \%$ (leakage error)
User accuracy: UA $=(94 / 98) * 100 \%=95.9 \%$ (misclassification error)

\subsection{Information Extraction Results and Analysis}

Based on multi-period GF-1 images, object-oriented crop information extraction method can extract corn and cotton, the major autumn crop of King County, Hengshui City, Hebei Province. The spatial distribution results are shown in Fig.7.It can be concluded that corn in Jingxian County, Hengshui City, Hebei Province has a wide distribution and covers almost the entire county. However, the distribution of cotton is fragmented and small in area, mainly distributed in the northwest of Jingxian County. The main reason for the less cotton planting area is the time-consuming and labor-intensive cotton cultivation. The price is greatly affected by the market and the growth period is greatly affected by the climate. 


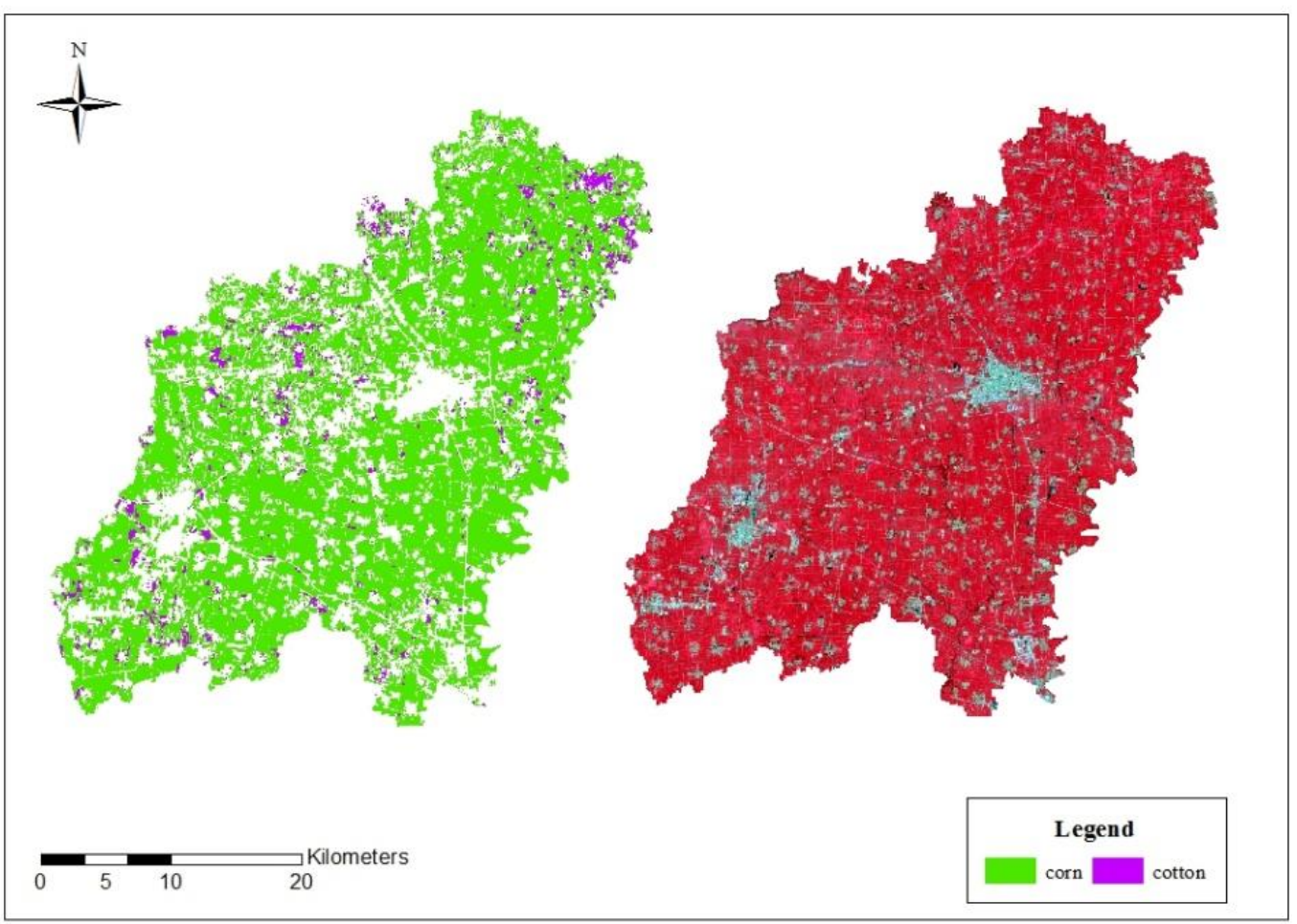

Figure 7. Spatial distribution of corn and cotton in Jinxian County in 2016

\section{CONCLUSION AND DISCUSSION}

Based on the multi-period GF-1 imagery, the object-oriented information extraction method was used to extract the spatial distribution of corn and cotton in Jingxian County, Hengshui City, Hebei Province in 2016. The following conclusions were drawn:

(1)Combining with the phenological stage of crop selection, the best time-series remote sensing data of the target crops can be selected to avoid interfering with crop effects and improve the precision of target crop extraction.

(2)The segmentation scale of crop based on GF-1 (16 m) images is more suitable for the setting of 10 in the plain area.

(3) The object-based information extraction method has better crop accuracy, which can provide the basis for the adjustment and optimization of crop planting structure in Jingxian County.

(4) The plot size and planting structure will also affect the accuracy of crop information extraction. For example, the plots of corn are more regular and concentrated, the cotton planting is smaller and scattered, resulting in higher precision of corn than cotton.

Due to the complex crop planting structure, especially the autumn harvest crops, there are some errors in the information extraction of corn and cotton. On the one hand, corn, cotton and other crops mixed phenomenon more mixed in the 16-meterscale images more serious in the future studies may consider the use of higher resolution data to extract autumn harvest crops. On the other hand, when the multi-period image data is selected, the selected images are not the key period images of the target crop or the interfering crop due to the influence of data quality and so on. All of these will have an impact on the crop identification. Therefore, in the follow-up study, other more effective analysis methods may be considered in phenology analysis, while other multi-source data are supplemented.

\section{ACKNOWLEDGEMENTS}

This research was supported by the National Key R\&D Program of China (No.2017YFB0503903).

\section{REFERENCES}

Hao, W. P., Mei, X. R., Cai, X. L., Du, J. T., Liu, Q., 2011.Crop planting extraction based on multi-temporal remote sensing data inNortheast China, Transactions of the CSAE, 27(1), pp. $201-207$.

Li, G., Jing, Y. S., Wang, L., 2014. Extraction of paddy planting areas based on MODIS vegetation index time series and linear spectral mixture model,Transactions of Atmospheric Sciences, 37(1),pp. 119-126.

Liu, K. B., Liu, S. B., Lu, Z. J., 2014. Extraction on cropping structure based on high spatial resolution remote sensing data,Chinese Journal of Agricultural Resources and Regional Planning, 35(1),pp. 21-26.

Li, W. G., Jiang, N., 2012. Extraction of winter wheat planting area by object-oriented classification method, Journal of Triticeae crops, 32(4), pp. 701-705.

Ma, L., Gu, X. H., Xu, X. G., 2009. Remote sensing measurement of corn planting area based on fielddata,Transactions ofthe CSAE, 25(8), pp. 147-151.

Ozdogan, M., 2010. The spatial distribution of crop types from modis data: temporal unmixing using independent component analysis, Remote Sensing of Environment, 114(6), pp. 11901204. 
Thenkabail, P. S., \& Wu, Z., 2012. An automated cropland classification algorithm (acca) for tajikistan by combining landsat, modis, and secondary data, Remote Sensing, 4(10), pp. 2890-2918.

Vintrou, E., Desbrosse, A., Bégué, A., Traoré, S., Baron, C., \& Seen, D. L., 2012. Crop area mapping in west africa using landscape stratification of modis time series and comparison with existing global land products, International Journal of Applied Earth Observation \&Geoinformation,14(1), pp. 83-93.

Verbeiren, S., Eerens, H., Piccard, I., Bauwens, I., \&Orshoven, J. V.,2008. Sub-pixel classification of spot-vegetation time series for the assessment of regional crop areas in belgium. International Journal of Applied Earth Observation \&Geoinformation, 10(4), pp. 486-497.

Zhang, J. K., Cheng, Y. P., Zhang, F. W., Yue, D. P.,Guo, X. X., \& Dong, H., 2012. Crops planting information extraction based on multi-temporal remote sensing images,Tansactions of the CSAE, 28(2), pp.134-141. 